Results Maximum IPAP achieved for period 2 was significantly higher than period 1 (median IPAP max achieved $=20 \mathrm{cmH}_{2} \mathrm{O}$ vs. 14 $\mathrm{cmH}_{2} \mathrm{O}$; Wilcox on rank sum test $\mathrm{p}=2.2 \times 10^{-16}$ ) and the maximum EPAP achieved for period 2 was higher than period 1 (median EPAP max achieved $=5 \mathrm{cmH}_{2} \mathrm{O}$ vs. $14 \mathrm{cmH}_{2} \mathrm{O}$; Wilcoxonrank sum test $\left.p=8.068 \times 10^{-6}\right)$.

Discussion We have previously shown that we achieved adequate therapeutic response with median IPAP max of 16.7 and median EPAP max of $5.2 \mathrm{cmH} 2 \mathrm{O}$ (Ali A et al. Pressure support in acute hypercapnic respiratory failure in an acute clinical setting. European Respiratory Journal 2011; 38:55. 683s.). However, as the ward-based, physiotherapy-intensive, multidisciplinary NIV service matures over an 8-year period, we are achieving significantly higher maximum IPAP and maximum EPAP. This is probably (a) in keeping with the increasing severity of AHRF that is being treated in the unit with similar in-hospital mortality (around $22 \%$ ) and (b) demonstrates a learning curve. Further analysis of population characteristics and comparison with units of similar size may give further insights intoorganisational learning in relation to NIV.

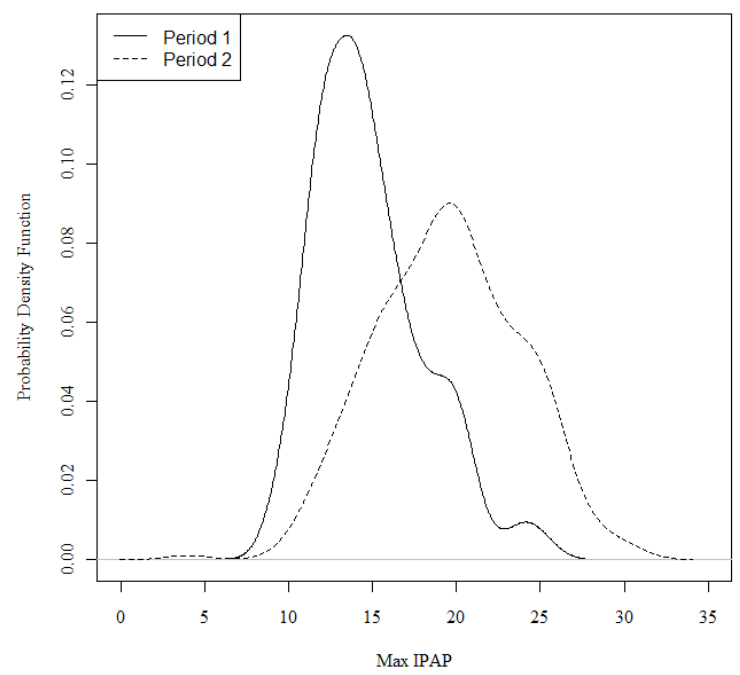

Comparison of the distribution of the maximum IPAP achieved

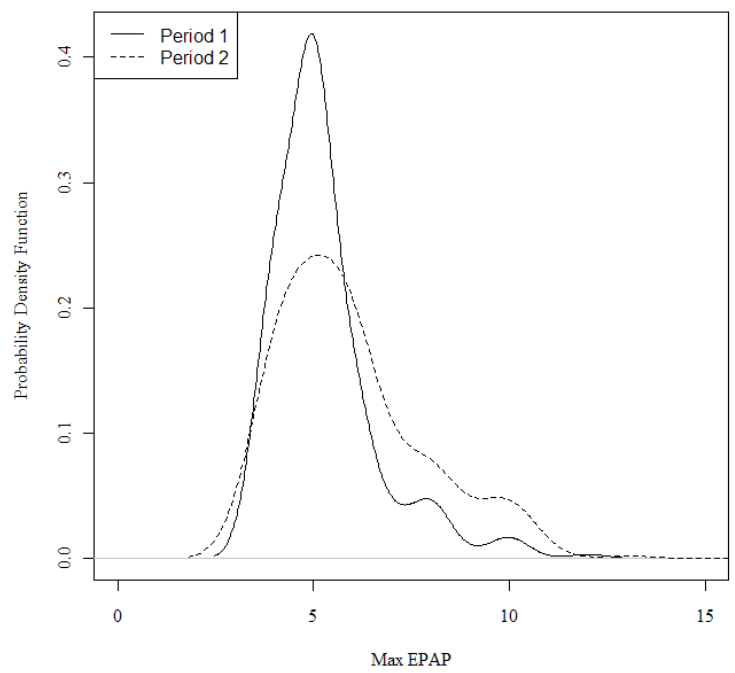

Comparison of the distribution of the maximum EPAP achieved

\section{P221 \\ TEMPORAL TRENDS IN SEVERITY AND IN-HOSPITAL MORTALITY IN ACUTE HYPERCAPNIC RESPIRATORY FAILURE (AHRF) AT A RESPIRATORY WARD-BASED NON- INVASIVE VENTILATION (NIV) UNIT}

doi:10.1136/thoraxjnl-2012-202678.282

${ }^{1} \mathrm{H}$ Lewis, 'C Wharton, 'S Agarwal, 'B Beauchamp, ${ }^{2 B}$ Chakraborty, 'D Banerjee, 'AM Turner, 'R Mukherjee. 'Birmingham Heartlands Hospital, Birmingham, UK; ${ }^{2}$ School of Mathematics, Univ. of Birmingham, Birmingham, UK

Introduction Use of NIV for AHRF in COPD, obesity related morbidity, chest wall and neuro muscular conditions have increased significantly over the past decade - there has been a documented $462 \%$ increase in acute NIV use in COPD (Chandra D et al. AJRCCM 2011) over 11 years in the United States with similar changes noted in smaller surveys in the UK. In the UK, this has led to the movement of NIV service provision out of critical care at ward-based NIV units. We felt it necessary to analyse temporal trends in the severity and outcomes of ward-based NIV practises.

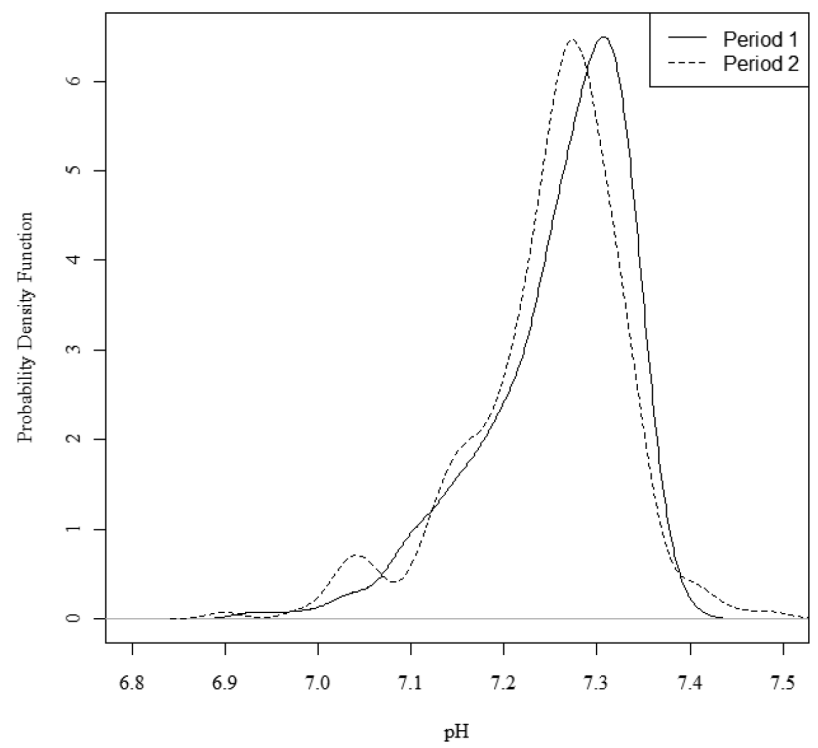

Wilcoxon rank sum test: $\mathrm{p}=0.03134$; $\mathrm{pH}$ significantly lower in Period 2

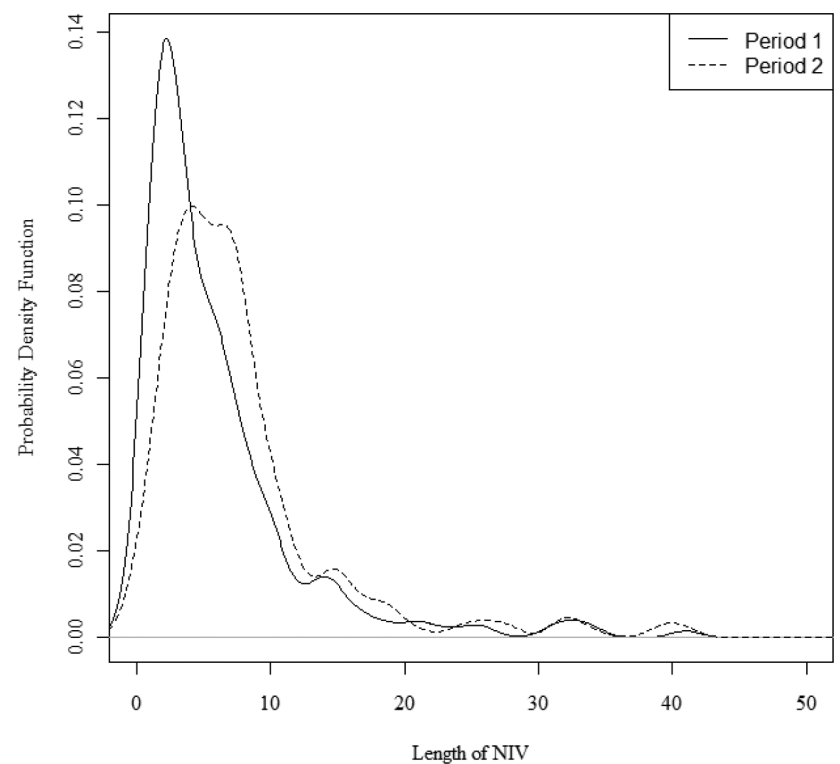

Wilcoxon rank sum test: $p=0.0000018$; Length of NIV is significantly higher in period 2

Abstract P221 Figure 1 
Methods Comparison of the in-house NIV registry data 01/08/2004-31/01/2006 (Period 1) with 01/01/2011 30/06/2012 (Period 2) at an 11-bedded ward-based NIV unit within a 1000-bedded hospital Trust in central England, looking at mortality, length(duration) of NIV and initial arterial blood $\mathrm{pH}$, the latter being widely accepted as a marker of AHRF severity.

Results There were 281 episodes of AHRF treated in Period 1 and 240 in Period 2 with similar distribution of gender (non-significant increase in the number of women); acute exacerbations of COPD constituted similar proportion (about 70\%) of dominant diagnosis behind AHRF in both periods (associated risk factor documentation, e.g. kyphoscoliosis not analysed); the initial arterial blood $\mathrm{pH}$ was significantly lower (median initial pH 7.280 vs 7.261; Wilcoxonrank sum test: $\mathrm{p}=0.03134$; $\mathrm{pH}$ significantly lower in Period 2); the mean length (duration) of NIV was significantly higher (median length of NIV 4.0 days vs 6.0 days; Wilcoxon rank sum test: $p=0.0000018$; Length of NIV is significantly higher in period 2), whilst in-hospital mortality was similar (21.6\% vs. $22.7 \%)$.

Discussion Our data confirm the clinical surmise that over time, our ward-based NIV unit is treating more severely ill patients with AHRF who are spending longer periods under acute NIV with no significant change in mortality. Further analysis of population characteristics, co-morbid risk factors for respiratory failure and Domiciliary NIV/Home Mechanical Ventilation practises as well as national trends in NIV use are needed to inform health policy/ strategies to deal with long term respiratory conditions.

\section{P222 A COMPARISON IN SERVICE PROVISION MODELS FOR VENTILATORY ASSESSMENT IN MOTOR NEURONE DISEASE PATIENTS}

doi:10.1136/thoraxjnl-2012-202678.283

H Yung, IE Smith, MG Davies. Papworth Hospital, Cambridge, UK

Specialist neurological MDT clinics improve outcomes in patients with motor neurone disease (MND) ${ }^{1}$. Non-invasive ventilation (NIV) was utilised in only $3 \%$ of this study group, but has since been shown to improve survival in selected patients ${ }^{2}$. With increasing referrals for NIV, our initial experience indicated a need for respiratory MDT input and a patient preference for day-case assessment. We established a clinic comprising regular specialist respiratory, nursing, physiotherapy and speech therapy assessment, ideally prior to the need for NIV. We undertake regular blood gases, overnight community sleep studies and lung function tests, in line with NICE recommendations. This study looks at our experience in transitioning to a dedicated MND day-case model, and how it has affected quality of care.

Methods We looked at two cohorts of MND patients seen over a 3-month period before (2009) and after (2012) the day-case clinic was established. There were 66 patients in the first cohort and 82 patients in the second. We compared the quality of service delivered by looking at the proportion of patients who had received the appropriate respiratory assessments. For lung function studies, we excluded those in whom mouthpiece testing was not possible (due to significant bulbar problems). For blood gases and sleep studies, all were included.

Results The current cohort comprised 9 new referrals and 73 follow-ups (55 male, average age $63 \mathrm{yrs}$ ). Of these, 53 (65\%) did not currently require NIV, 27 (33\%) were already established on NIV and $2(2 \%)$ received tracheostomy ventilation. As expected, there was a major shift towards day-case attendance (from 33\% in 2009 to $82 \%$ in 2012). There was a clear increase in objective screening tests. Table 1 shows the proportion of eligible patients receiving these tests.

Discussion These results show that a dedicated day-case MDT clinic improves the ventilatory assessment of MND patients. Whilst the uptake of NIV and, ultimately, survival, can only be determined in due course, we have previously shown a significant increase in NIV uptake in our MND patients (70\% in 2011). We feel that the greater availability of objective testing, demonstrated here, and the structured approach of the service has contributed to this.

1. Traynor BJ et al. J Neurol Neurosurg Psychiatry 2003.

2. Bourke SC et al. Lancet Neurology 2006.

Abstract P222 Table 1

\begin{tabular}{|c|c|c|}
\hline Day-case & $\begin{array}{c}2009 \\
(n=22,33 \% \text { total })\end{array}$ & $\begin{array}{c}2012 \\
(n=67,82 \% \text { total })\end{array}$ \\
\hline Blood Gases (\%) & 77 & 96 \\
\hline Sleep studies (\%) & 45 & 93 \\
\hline Lung function (\%) & 77 & 90 \\
\hline $\begin{array}{c}\text { Overall } \\
\text { (incl. inpatients) }\end{array}$ & $\begin{array}{l}2009 \\
(n=66)\end{array}$ & $\begin{array}{l}2012 \\
(n=82)\end{array}$ \\
\hline Blood Gases (\%) & 80 & 96 \\
\hline Sleep studies ( $\%$ ) & 68 & 94 \\
\hline Lung function ( $\%$ ) & 62 & 91 \\
\hline
\end{tabular}

P223 NIV....A KISS OF LIFE

doi:10.1136/thoraxjnl-2012-202678.284

F Rauf, I Qureshi, A Ali. University Hospital of Coventry \& Warwickshire, Coventry, UK

Background Non-invasive ventilation (NIV) can be a lifesaving intervention and this is recommended treatment for acute hypercapnoeic respiratory failure. However it is thought to be a distressing intervention by some patients \& families. We performed a survey of patient's perception of acute ward based NIV and its effect on their symptoms.

Method With a brief questionnaire we enquired patients how they felt when NIV was commenced and positive or negative effects of NIV on various symptoms. 20 consecutive patients who were admitted for acute NIV from February to April 2012 were included. A record was also made about the place where NIV was initially instituted.

Findings $75 \%$ patients received NIV for COPD exacerbations. $65 \%$ patients were NIV naive. $90 \%$ of patients recalled initiation of NIV. $55 \%$ of treatments were started in emergency department (ED). $63 \%$ of $\mathrm{ED}$ patients and $77 \%$ of ward patients recalled that they were explained about the treatment before starting.

$90 \%$ patients recognised NIV as a lifesaving intervention and $90 \%$ wanted to receive this again if needed acutely and $65 \%$ would accept domiciliary NIV if offered.

$85 \%$ reported improvement in breathing, $40 \%$ felt reduction in tiredness \& headaches and $5 \%$ felt improvement in exercise tolerance. However $5 \%$ patients felt that NIV has actually worsened their breathing, another $5 \%$ felt that there was no improvement in symptoms at all.

The commonest negative feelings were claustrophobia (45\%) followed by fatigue (40\%), sleeplessness (35\%), inability to breathe $(30 \%)$ \& feeling panicked $(25 \%)$.

Some interesting comments were,

"Like being given a kiss of life"

"Lifesaving piece of equipment which is not a comfort ride but it is necessary"

"I know this is horrible but I shall always say go for it mate". Interpretation:

Almost all patients will feel distressing symptoms including agitation and claustrophobia in the beginning of treatment but these 